\title{
Seizure Semiology: Value in Identifying Seizure Origin
}

\author{
Mohammed M.S. Jan, John P. Girvin
}

\begin{abstract}
The diagnosis of epilepsy depends upon a number of factors, particularly detailed and accurate seizure history, or semiology. Other diagnostic data, consisting of electroencephalography, video-monitoring of the seizures, and magnetic resonance imaging, are important in any comprehensive epilepsy program, particularly with respect to lateralizing and localizing the seizure focus, if such a focus exists, and with respect to determining the type of seizure or seizure syndrome. The aim of this review is to present a survey of important semiologic characteristics of various seizures that provide the historian with observations, which help to lateralize and localize epileptic zones. Clinical semiology is the starting point of understanding a seizure disorder and making the diagnosis of epilepsy. While it may not provide unequivocal evidence of localization of the epileptic focus, nevertheless it usually directs subsequent investigations, whose concordance is necessary for the ultimate localization.
\end{abstract}

RÉSUMÉ: Séméiologie des crises convulsives : importance d'identifier l'origine des crises d'épilepsie. Le diagnostic d'épilepsie repose sur un certain nombre de facteurs, principalement sur une histoire détaillée et exacte des crises c.-à-d. la séméiologie. Les autres données sur lesquelles repose le diagnostic sont l'électroencéphalographie (ÉEG), l'enregistrement sur vidéo et l'imagerie par résonance magnétique (IRM) qui sont importants dans un protocole complet d'évaluation, surtout pour la latéralisation et la localisation du foyer épileptique le cas échéant et pour l'identification du type d'épilepsie ou de syndrome épileptique. Le but de cette revue était de présenter les caractéristiques séméiologiques importantes des différentes épilepsies qui fournissent au clinicien les observations aidant à déterminer la latéralisation et la localisation des zones épileptogènes. La séméiologie clinique est le point de départ de la compréhension d'un désordre épileptique et du processus diagnostique. Bien qu'elle ne fournisse pas toujours une indication non équivoque sur la localisation du foyer épileptique, elle oriente habituellement l'évaluation du patient et la concordance des observations est nécessaire pour sa localisation.

Can. J. Neurol. Sci. 2008; 35: 22-30

The diagnosis of epilepsy is dependent upon a very detailed and accurate history. ${ }^{1}$ The recording of this chronological sequence of recurrent, transient, self-limited, involuntary, alteration in the neurological state, i.e., the semiology, must be meticulously sought. It is the quality of this inquiry that allows one to understand the patient's complaints and to provide the diagnosis of epilepsy. Epilepsy is a clinical diagnosis and there is no single investigation that can accurately exclude or diagnose epilepsy. ${ }^{1,2}$ The clinical information not only makes the diagnosis, but it also allows the seizures to be classified. An accurate semiologic history is not only important in the diagnosis, but it is most important in determining the region of the brain from which the seizures are arising in patients with intractable epilepsy who are being considered for surgical management. ${ }^{3}$ Certainly one would not minimize the importance of electroencephalography (EEG), video-monitoring, and magnetic resonance imaging (MRI) in localization of seizure foci $^{3-7}$ but discordance of the localization of the clinical

From the Department of Pediatrics (MMSJ), King AbdulAziz University Hospital, and Department of Neurosciences (MMSJ, JPG), King Faisal Specialist Hospital \& Research Center, Jeddah, Saudi Arabia.

Received May 18. 2007. Final Revisions Submitted October 9, 2007. Reprint requests to: Mohammed M.S. Jan, Department of Pediatrics (Neurology), King AbdulAziz University Hospital, P O Box 80215, Jeddah 21589, Kingdom of Saudi Arabia. 
semiology with these other tests within the investigative armamentarium raises suspicion about the accuracy of the localization.

\section{Seizure History}

As already emphasized, there is no substitution for a carefully obtained history when one initially encounters a patient with epilepsy. Meticulousness in seeking an accurate semiology has many rewards. It provides one of the lost aspects of the Art of Medicine in today's healthcare environment but, in addition to serving the patient it rewards the young epileptologist and sets what hopefully will be a life-long discipline in history taking, and lastly it provides the necessary information to make a diagnosis and to classify the epileptic condition. A previous diagnosis of epilepsy should not necessarily be accepted without a confirmatory history, if there are any reasons to question its quality. Clinical experience is replete with examples in which inaccurate initial histories are accepted and transferred from one document to another, until the suspicious historian realizes that there is discordance in the subsequent investigation, course, diagnosis, and/or management of the patient's seizure disorder. Unfortunately this occurs far too often in residency training programs where the rigid discipline of high quality history taking has been allowed to be compromised. The first encounter often requires: 1) follow-up visits with the patient, per se, who may be able to obtain additional information from individuals who have witnessed her/his seizures, 2) phone calls to other witnesses, such as a family member or a friend, 3) formal consultations with such witnesses, or 4) the request of home video taping of seizures when this is possible. The combination of one or all of these strategies should allow the attentive examiner to make as accurate a diagnosis as is clinically possible. In the case of very young patients the physician should not slip into the practice of not fully including the patient in the conversation, as the child can often provide valuable additional information, which otherwise might not be realized. In all the strategies, the request for the interviewees to mimic the patients' seizures may actually be the most important information leading to the diagnosis, lateralization and localization! The time of the day when seizures might occur is important as some occur predominantly in sleep (benign Rolandic seizures, tonic seizures in Lennox Gastaut syndrome, and frontal lobe seizures). In order to optimize the quality of the information gained during history taking it is worth remembering that each event may potentially have four stages: preictal, ictal onset (aura), ictus, and postictal as shown in Table 1.

1-Pre-ictal Phase: The premonitory phase includes the socalled provoking or precipitating factors such as fever, illness, high altitude, lack of sleep, lack of compliance, menstruation, and head injury. However, this stage may also include symptoms that may be somewhat controversial and defy placement in the ictal onset phase. The controversy is usually associated with the event lasting an inordinate length of time, e.g., tens of minutes, hours or even, in some cases, days. These are referred to as prodromal symptoms and should not be confused with seizure onset. ${ }^{8}$ Such events are not common, but should not be rejected out of hand, as very occasionally they may form part of the true seizure semiology, in which case they may have localizing value with respect to seizure onset (see below). Some examples of such
Table 1: Seizure history taking and its significance

\section{FEATURES}

\section{1- Before seit}

Prodrome

Environment of occurrence

Time of the day

(e.g., upon awakening)

Precipitants or triggers

Association with sleep

2- At the beginning of the seizure Aura

Focal onset

3- During the seizure

Progression

Aphasia

Awareness \& consciousness

Duration

4-Postictal phase

Confusion / amnesia

Unilateral headache

Weakness (Todd's paresis)

Visual field defect

Dysphasia

\section{SIGNIFICANCE}

May precedes generalized tonic clonic seizures To exclude syncope or pseudoseizures Myoclonic or primary generalized epilepsy

Reflex or photosensitive epilepsy

Rolandic or frontal lobe epilepsy

Lobe of origin (e.g., occipital if visual)

Lateralization and/or localization (Tables $3 \& 4$ )

Identify the involved brain regions Dominant hemisphere

Simple versus complex partial or generalized

Status epilepticus

Suggests complex partial or generalized

Ipsilateral seizure origin Contralateral hemispheric origin

Occipital lobe involvement Dominant hemispheric involvement include headaches, behavioural irritability, and personality change.

2- Ictal Onset: Because of the dramatic aspects of a generalized tonic-clonic seizure, which often is thought, at least transiently, to be an agonal event by many lay people, there is a tendency to consider this as the "seizure" in totality, with no significance attached to a possible importance of the preceding or post-ictal symptomatology. However, as already indicated and as well known, the very first event in the chronological sequence of events in a seizure is the most important feature for the localization of a seizure focus, in the case of partial seizures. The history of any brief focal signs or symptoms (aura) at the beginning of the more dramatic seizure must be obtained. When a history is considered to be of poor quality the most common criticism is the failure to obtain a satisfactory determination of this very first event in the semiology, when in fact there is such 
Table 2: Differentiating staring due to absence from that of complex partial seizures

\begin{tabular}{lll}
\hline FEATURES & ABSENCE & COMPLEX PARTIAL \\
Sleep activation & None & Common \\
Hyperventilation & Induces the seizures & No activating effect \\
Seizure frequency & Frequent, many per day & Less frequent \\
Seizure onset & Abrupt & Slow \\
Aura & None & If preceded by a simple partial seizure \\
Automatism & Rare & Common \\
Progression & Minimal & Evolution of features \\
Cyanosis & None & Common \\
Motor signs & Rare, or minimal & Common \\
Seizure duration & Brief (usually <30 sec) & Minutes \\
Postictal confusion or sleep & None & Common \\
Postictal dysphasia & None & Common in seizures originating from the \\
& & dominant hemisphere \\
\hline
\end{tabular}

an event. The patient usually refers to this part of the seizure as the "warning". The historian needs to be perfectly satisfactorily convinced that indeed the initial event has been elucidated. This requires good listening ability and intelligent questioning by the clinician. ${ }^{9}$ This importance can be appreciated in an example of a semiology that consists of an abnormal hallucinatory taste, followed by a rising epigastric sensation, followed by deviation of the head and eyes, and then clonic movements of the thumb. Each of these alone may lead to the conclusion that the seizure focus is in a different location. For example, if the clonic movements of the thumb are interpreted as the initial event then the contralateral dorsolateral motor neocortex would be the suggested focus, as opposed to the contralateral premotor cortex (head and eye deviation), the inferomesial temporal lobe (rising epigastric sensation), or the contralateral supraSylvian inferior Rolandic cortex (abnormal taste). In the foregoing example of the simple partial seizure onset with four different components the latter three events are not without importance, as they are interpreted as reflecting the spread of the seizure discharge. Such spread of the seizure over the cortex has the potential of detracting somewhat from the certainty of the clinical localization. As outlined in the foregoing paragraph the four components noted in the example of the seizure semiology can be attributed to relatively specific cortical areal representations. Such cortical areas, which are associated with clinically recognizable function, have come to be known as so-called "functional", or "eloquent", cortex, in contrast to those areas of cortex, which have no such clearly recognizable function; the latter have been labeled by some as "silent", or "non-eloquent", cortex. The neurophysiological student will immediately recognize the arbitrary and somewhat naïve nature of such an assumption, especially if that assumption carries the implication that this is indeed physiologically functionless cortex. However, putting that aside this differentiation does have clinical use, so long as one remembers that a seizure focus may begin in this so- called silent cortex with the first clinical event being recognized when the spread of the seizure impinges upon an area of clinically "functional" cortex. Thus, while in theory one might consider this as an example of false localization, nevertheless the clinical usefulness of localization of epileptic foci from semiology derives from the fact that while perhaps an area of silent cortex is the focus, nevertheless this is usually in the immediate vicinity of the nearby involved "functional" cortex, which has led to the clinical localization.

3- Ictal Phase: The ictus is usually associated with an alteration in consciousness. This alteration may be a loss of consciousness, as in primary generalized tonic-clonic seizures or simply an "altered" state, which is characteristically seen in complex partial seizures of temporal lobe origin. The alterations in the latter may be such that the naïve observer may interpret the patient's state as one of full consciousness, particularly when associated automatic behavior (automatisms) appears normal, or near normal (see below). Staring due to complex partial seizures should not be confused with that of absence seizures. Hyperventilation for three minutes can induce an absence seizure and results in quick diagnosis during the clinic visit. Additional helpful differentiating features are summarized in Table 2. There are times when referral notes will refer to two or three different seizure types. It is very important to sort this out, as more than one seizure type suggests more than one seizure focus. Bitemporal seizures may occur for reasons which are not the subject of this paper, but other instances of more than one epileptic focus in a given patient is a very, very uncommon eventuality. Usually in these instances the two or three seizure types are simply extensions of single seizure semiology. Perhaps the commonest such example is a typical complex partial seizure with simple partial onset and secondary generalization, in which an interpretation is that these three components of a single seizure semiology represent three separate seizure types, as opposed to simply an extension of the same seizure focus. 
4- Post-ictal Phase: The post-ictal period may also have clinically valid localizing factors, even though they may be seen in this phase at the end of the seizure. These post-ictal changes take the form of deficits of function. In a primary generalized seizure, for example, there may be a post-ictal deficit with localizing value. For example, post-ictal weakness (Todd's paresis) or visual deficits will point to involvement of the associated functional cortex in the contralateral hemisphere. Post-ictal dysphasia will suggest involvement of the dominant hemisphere. It is not uncommon to see a patient whose referral notes have clearly stated the diagnosis of primary generalized seizures, only to find out upon close questioning of those witnessing the post-ictal periods of the patient's seizures valuable information of localizing and/or lateralizing value in the diagnosis of partial seizures. Severe post-ictal headache is most common following occipital lobe or generalized tonic-clonic seizures.

\section{Seizure Semiology}

While the quality of the determination of the semiology, as derived from the history, may be superseded by semiological features identified by good quality video- monitoring, yet the clinical semiology, along with EEG evaluation, medical imaging (MRI) and neuropsychological assessment are all important in identifying the epileptic focus in patients with intractable epilepsy who are being considered for possible epilepsy surgery. ${ }^{3}$ It is the concordance of these assessments, which is usually necessary for the recommendation of epilepsy surgery; it has similar importance in the prognosis of such surgery. $6,7,10,11$ In discussing semiology it is helpful to consider some common categories of semiologic features, especially when differentiating frontal lobe (FL) from temporal lobe (TL) seizures - the two regions most frequently affected by partial epilepsy and the most common difficult differentiation of partial seizures. Using the features outlined in Table 3, seizures have been reported to be reasonably accurately localizable to the frontal or temporal lobes in the majority of patients. ${ }^{12,13}$ Other important lateralizing and localizing semiologic features of partial and secondarily generalized seizures are summarized in Table 4. They can be grouped into one of the following four categories, 1) automatism, 2) speech, 3) motor, and 4) autonomic features.

1- Automatism: Automatisms are repetitive involuntary, purposeless or semi-purposeful movements that are usually inappropriate, but indeed occasionally may simulate relatively normal movements. The latter are usually recognized as being abnormal by their inappropriateness under the circumstances at the time. Oro-alimentary automatisms, consisting of lip smacking, sucking, swallowing, and/or chewing movements, especially occurring near the beginning of a seizure, are suggestive of temporal lobe epilepsy (TLE), originating in the limbic (inferomesial) portion of the lobe. While these automatisms have localizing value, yet they have no lateralizing value. Unilateral eye blinking (winks) is a rare phenomenon that is reported to have ipsilateral localizing value onset. ${ }^{14}$ It should not be confused with hemi-facial rhythmical repetitive clonic jerking associated with contralateral motor cortex onset.

2- Language Abnormalities: Speech disturbances during seizures include receptive, expressive, or global dysphasia. The lateralizing value of ictal speech preservation or arrest is described in Table 4. Ictal verbalization, consisting of understandable names, verbal phrases or sentences should be distinguished from guttural vocalizations such as moaning, grunting, and/or screaming. While vocalizations have no specific lateralizing value, nevertheless they appear to be more

Table 3: Semiology of frontal versus temporal lobe seizures

\section{FEATURES}

Seizure frequency

Sleep activation

Seizure onset

Progression

Initial motionless staring

Automatisms

Bipedal automatism

Complex postures

Hyperkinetic motor signs

Somatosensory symptoms

Speech

Seizure duration

Secondary generalization

Postictal confusion

Postictal dysphasia

\section{FRONTAL LOBE}

Frequent, often daily

Characteristic

Abrupt, explosive

Rapid

Less common

Less common

Characteristic

Early, frequent, and prominent

Common

Common

Loud vocalization (grunting, screaming, moaning)

Brief

Common

Less prominent or short

Rare, unless it spreads to the dominant temporal lobe

TEMPORAL LOBE
Less frequent
Less common
Slower
Slower
Common
More common and longer
Rare
Late, less frequent and less prominent
Rare
Rare
Verbalization speech in non-dominant seizures
Longer
Less common
More prominent and longer
Common in dominant
temporal lobe seizures


Table 4: Important semiologic features and their lateralizating and/or localizing value

\begin{tabular}{|c|c|}
\hline Semiologic features & $\begin{array}{l}\text { Lateralization and/or } \\
\text { localization }\end{array}$ \\
\hline \multicolumn{2}{|l|}{ 1- Automatism } \\
\hline Oral automatism & $\begin{array}{l}\text { Temporal lobe, typically } \\
\text { hippocampal }\end{array}$ \\
\hline Jnilateral limb automatism & Ipsilateral to seizure origin \\
\hline Unilateral & Ipsilateral to seizure origin \\
\hline Bipedal automatisms & Frontal lobe seizures \\
\hline Ictal spitting or drinking & Right temporal seizures \\
\hline Ictal laughter (Gelastic) & $\begin{array}{l}\text { Hypothalamic, mesial temporal } \\
\text { or frontal cingulate origin }\end{array}$ \\
\hline Postictal nose wiping & $\begin{array}{l}\text { Ipsilateral temporal lobe } \\
\text { seizures }\end{array}$ \\
\hline Postictal cough & Temporal lobe seizures \\
\hline $\begin{array}{l}\text { 2- Language abnormalities } \\
\text { Ictal speech arrest }\end{array}$ & res, usually \\
\hline Ictal speech preservation & $\begin{array}{l}\text { Temporal lobe seizures, usually } \\
\text { non-dominant hemisphere }\end{array}$ \\
\hline Postictal dysphasia & $\begin{array}{l}\text { Dominant hemisphere } \\
\text { involvement }\end{array}$ \\
\hline \multicolumn{2}{|l|}{ 3- Motor abnormalities } \\
\hline Early nonforced head turn & Ipsilateral to seizure origin \\
\hline urn & eizure origin \\
\hline Eye & eizure origin \\
\hline Foc & $\begin{array}{l}\text { Contralateral to seizure origin, } \\
\text { peri-rolandic }\end{array}$ \\
\hline Asyn & Ipsilateral to seizure origin \\
\hline . & Contralateral to seizure origin \\
\hline Tonic limb posturing & Contralateral to seizure origin \\
\hline Fenc & $\begin{array}{l}\text { Contralateral frontal lobe } \\
\text { (supplementary motor) seizures }\end{array}$ \\
\hline Figure & $\begin{array}{l}\text { Contralateral to the extended } \\
\text { limb, usually temporal lobe }\end{array}$ \\
\hline & Contralateral to seizure origin \\
\hline & Contralateral to seizure origin \\
\hline & \\
\hline & Rig \\
\hline & Right temporal seizures \\
\hline Piloerection (goose bumps) & Left temporal seizures \\
\hline
\end{tabular}

commonly seen in frontal lobe seizures. ${ }^{15,16}$ Naming defects (dysnomia) and paraphasic errors are easily demonstrable during seizures. ${ }^{17}$ Postictal dysphasia is a very useful lateralizing sign, but it may not be detected unless the monitoring staff routinely specifically tests post-ictal speech function (Table 5). Post-ictal dysphasia, like onset or ictal dysphasia, points to a focus in the dominant hemisphere. Non-dominant hemisphere seizures can also interfere with speech function. ${ }^{18}$ It may be simply on the basis of post-ictal mental confusion..$^{19}$ Speech arrest may occur at the onset of a seizure from involvement of the speech areas, but can also occur from involvement of the inferior Rolandic (sensory-motor) cortex and the supplementary motor area. ${ }^{20}$

3- Motor Abnormalities: Motor signs may be positive, involving involuntary clonic and/or tonic movements, abnormal posturing, dystonia, and head and/or eye deviation. Negative motor signs include muscle weakness or paralysis. Positive motor signs should be distinguished from automatisms, which were described earlier. Whereas in the latter there are usually some fragments, albeit perhaps very brief, which could be construed as semi purposeful or purposeful movements, no such movements occur in the case of clonic and tonic movements. When abnormal bilateral motor activity occurs, a careful examination of the time of onset on each side and the symmetry of the movement between the sides is warranted. Early occurrence or more vigorous activity on one side suggests a contralateral focus, e.g., similar to the presence of a post-ictal hemiparesis. While early asymmetric motor activity usually correlates with the seizure origin, late asymmetry may suggest seizure propagation. ${ }^{13}$ Head deviation at the onset of a seizure in the presence of normal consciousness is a strong indication of a contralateral mid frontal dorsolateral cortical focus. ${ }^{21}$ Nonforced head rotation - a voluntary-like head turn - when it appears early is reported to be often associated with ipsilateral hand automatisms, ${ }^{22}$ and is usually toward the hemisphere of seizure origin. Be aware of the initial head turn that may be no more than a response to an external stimulus in a partially responsive patient. Later head turn is due to seizures arising from the contralateral hemisphere, more commonly accompanying temporal lobe than frontal lobe seizures, occurring in the later stage of the seizures. ${ }^{23}$ Eye deviation is usually associated with forced head turning and occurs in the same direction. Striking head and eye deviation can occur with contralateral occipital seizures $;{ }^{24}$ these may even be accompanied by turning of the upper body. Post-ictal head deviation is assumed to be passive and thus suggestive of ipsilateral frontal lobe involvement. Focal

Table 5: Examination of patients during the seizure for semiologic characteristics

\begin{tabular}{ll}
\hline Examination & Significance \\
$\begin{array}{l}\text { Response to communication } \\
\text { Speech (naming, reading) }\end{array}$ & $\begin{array}{l}\text { Level of awareness } \\
\text { Dominant hemispheric } \\
\text { involvement }\end{array}$ \\
$\begin{array}{c}\text { Memory (presenting words } \\
\text { or phrases for later recall) }\end{array}$ & $\begin{array}{l}\text { Temporal lobe involvement } \\
\text { Distractibility }\end{array}$ \\
$\begin{array}{c}\text { Response to passive } \\
\text { eye opening }\end{array}$ & $\begin{array}{l}\text { To exclude pseudoseizure (tight } \\
\text { closure) }\end{array}$ \\
$\begin{array}{c}\text { Response to physical } \\
\text { stimulation }\end{array}$ & Attention, motor dysfunction \\
$\begin{array}{c}\text { Weakness or lack of motor } \\
\text { control }\end{array}$ & Contralateral seizure origin \\
Plantar extensor response & Post-ictal paresis \\
\hline
\end{tabular}


clonic jerking is one of the indisputable localizing and lateralizing features, with the focus situated in the contralateral motor cortex, with further localization within that cortex from a knowledge of the homunculus, i.e., facial twitching from the inferior cortex, hand clonus from the middle dorsolateral motor cortex and clonic leg movements from the medial motor cortex. Such focal clonic activity may be seen late in temporal lobe seizures, assumed to be the result of spread of the epileptic discharge out of the temporal lobe. ${ }^{25}$ "Asymmetric ending of clonus" refers to unilateral clonic jerking occurring in a terminal phase of generalized seizures,${ }^{26}$ interpreted as the final clonus occurring ipsilateral to the seizure onset, as a result of spread to, and termination in, the contralateral hemisphere. In contrast to the localizing significance of clonic motor activity, tonic movements do not have predictable specificity of localization and lateralization. Sustained unilateral dystonic posturing of the arm and leg has been attributed to spread to the contralateral basal ganglia. ${ }^{27}$ Typical hand posture involves wrist flexion, finger flexion at the metacarpo-phalangeal joints, finger extension at the inter-phalangeal joints, and thumb adduction. Unilateral tonic limb posturing is suggestive of contralateral hemispheric seizure origin. Asymmetric tonic limb posturing (figure of 4 Sign) is usually observed during the early tonic phase of partial seizures as they become secondarily generalized..$^{28}$ One arm is extended at the elbow while the other is flexed at the elbow, giving the appearance of a figure of 4 . Both arms are slightly raised in front of the chest. The seizure onset is contralateral to the extended limb, and is usually temporal lobe in origin. Unilateral ictal limb paresis may or may not persist into the postictal phase and is associated with contralateral hemispheric origin. ${ }^{29}$ Postictal weakness (Todd's paresis) suggests contralateral hemispheric origin. The weakness may not be obvious to the observer; therefore, power should be specifically tested during and after seizures (Table 5). Asking the patient to point to the ceiling with each hand would test for weakness, as well as, for the level of awareness by following the command.

4- Autonomic symptomatology: Postictal vomiting has no lateralizing value; however, early ictal vomiting (ictus emesis) may suggest right temporal lobe origin. ${ }^{30}$ Ictal vomiting can also be seen in the benign occipital epilepsies. Ictal urinary urge and piloerection (goose bumps) are rare and are usually associated with temporal lobe seizures as shown in Table 4. ${ }^{31,32}$

\section{Temporal Lobe Seizures}

Temporal lobe seizures are the commonest site of origin of partial seizures and account for about two thirds of cases of intractable epilepsy that become managed surgically in our experience. The seizures are typically complex partial, with or without simple partial onset. The semiologic features of TLE, some of which have been noted earlier, are nearly boundless. Jackson described the so-called "dreamy state" in seizure semiology in the 19th century. ${ }^{33}$ With the comparison of clinical observations and responses to intraoperative stimulation studies, the Montreal school described these psychic phenomena as interpretative illusions or experiential hallucinations. ${ }^{34-37}$ Oroalimentary automatisms are common, occurring in approximately $70 \%$ of cases of limbic (hippocampal) seizures compared to $10 \%$ of patients with extra-limbic seizures. ${ }^{38}$
Unilateral dystonic posturing of an arm is classical of contralateral temporal lobe epilepsy. ${ }^{39}$ This is often present with other more easily appreciated automatisms in the other arm, e.g., repetitive purposeless finger movements. This has led to the appreciation that unilateral upper limb automatisms have localizing value, implicating the ipsilateral TL. Commonly the automatisms appear rather symmetrical initially, the clearly dystonic limb appearing later in the established automatism. However, unilateral automatisms without contralateral dystonia have a lower lateralizing value. Postictal nose rubbing or wiping is an uncommon form of unilateral limb automatism resulting from parasympathetic overactivity. ${ }^{40}$ It is usually associated with ipsilateral temporal lobe seizures. Postictal coughing may also be associated with TL seizures. Olfactory auras usually consist of poorly recognizable, always unpleasant, foul smell and historically were attributed to the uncus of the temporal lobe, thus becoming known as "uncal" or "uncinate" fits. ${ }^{33}$ More recently it has been realized that this localization may be less specific than originally thought. Fear is another limbic aura, considered to be amygdaloid in origin. ${ }^{35,37,41}$ For this localization, it must be "primary fear", and not simply the often secondary fear that is experienced by the epileptic patient in response to the realization that "another" seizure is about to occur. Primary fear cannot be reduced, or altered, by the patient. Usually there is an accompanying fearful facial countenance. Patients with left temporal lobe seizures cannot read normally post-ictally. Post-ictal dysphasia is more common in TLE than in frontal lobe foci. ${ }^{42}$ The relationship of behavioral aggression and TLE has been the subject of a broad cross section of the literature. ${ }^{43-45}$ These behavioral oddities may also include sexual features, fetishes, and hypergraphia. ${ }^{46,47}$ Temporal Lobe seizures can, and have been, separated by some into the much more common $(80 \%+)$ limbic, or antero-infero-mesial, and neocortical, TLE, depending upon origins in the amygdala/entorhinal/hippocampal area and neocortex, respectively. The auditory illusory auras may originate from either side temporal neocortex. ${ }^{37,48}$

\section{Frontal Lobe Seizures}

The seizures of frontal lobe epilepsy (FLE) are usually briefer, are associated with less post-ictal confusion, are more motor in characteristics, are more likely to be involved with secondary generalization, are less likely to demonstrate psychic/emotional/affective phenomena, are more likely to exhibit a rapid onset and offset, and are more likely to occur nocturnally than other partial seizures as shown in Table $3 .{ }^{49}$ Geier and colleagues noted that the automatisms of frontal lobe epilepsy suggested that they were of a "forced nature", 50 hence, they exhibit some differences from those of other origins. These collectively stand in particular contrast to temporal lobe seizures. While there are no clearly pathognomonic features of FLE, ${ }^{1}$ apart from the clearly localizable clonic seizures of the motor cortex, yet some generalizations with respect to the semiology of seizures arising in the frontal lobe may be made regarding their sites of origin. The frontal areas that emerge, representing potentially different are: 1) fronto-polar, 2) orbito-frontal, 3) premotor, including the supplementary motor area (SMA), 4) dominant opercular, and 5) Rolandic. The latter is more logically considered along with its post-central sensory counterpart 
(somatosensory cortex), under the designation of "Rolandic", or central, seizures. In the other categories of seizures there may be various combinations of the general characteristics of frontal lobe seizures.

1- Fronto-polar: Seizures of fronto-polar origin are often from scars following head injuries. They have the greatest likelihood of simply being characterized by what appear clinically to be primary generalized seizures, e.g., generalized tonic-clonic seizures without a simple partial onset. However, as noted in the foregoing, they may have some of the general characteristics of FLE, especially contralateral head deviation.

2- Orbito-frontal: Orbito-frontal seizures may have semiology that mimics temporal lobe seizures in which case the origin is usually attributed to the posterior part of the orbital cortex. ${ }^{52}$ Once again, however, it may involve, in various combinations, other frontal lobe semiology, especially contralateral head and eye deviation.

3- Premotor: Head and eye deviation with varying bilateral tonic posturing is the commonest seizure characteristic of premotor seizures. When the deviation occurs at the onset of the seizure when consciousness is intact it has significant localizing value to the contralateral frontal cortex. ${ }^{21}$ When it occurs during the seizure in an unconscious patient, it is of little localizing value. Those seizures arising in the mid part of the frontal lobe have a prominent bilateral tonic posturing. Bipedal automatisms may take the form of symmetric bicycling or kicking movements. ${ }^{53}$ Prominent leg movements favor involvement of the supplementary motor area. ${ }^{54}$ The so-called "fencing posture" is classically associated with the contralateral FL, particularly the SMA. ${ }^{55}$ The SMA is really a specialized part of the premotor area, involving the cortex immediately anterior to the precentral sulcus medially and at the upper part of the dorsolateral cortex. It is specialized in that is represents a second motor homunculus. This complex posture is characterized by abduction, external rotation, and partial flexion of the contralateral arm at the shoulder, contralateral deviation of the head and eyes such that they "look at" the contralateral arm, extended ipsilateral arm downwards and backwards, and with the feet apart so as to support the partially contralaterally rotated trunk. Occasionally, the upper limb is also flexed at the elbow with the hand raised to the face that has turned forcefully towards it. There is occasionally guttural, ill-understood speech.

4- Dominant opercular: A seizure origin involving the supraSylvian dominant frontal cortex usually begins with an alteration in speech. The alteration may be typical dysphasic speech, a form of non-specific guttural speech, or an arrest of speech. As noted earlier, it is an important, localizing feature post-ictally when there is dysphasia.

5-Rolandic: The pre- and post-central gyri are considered as a unit, as the majority of Rolandic seizures combine both motor and sensory components, which carry the clear cut features of involvement of the contralateral Rolandic cortex. Sensory features can be positive (e.g. pins and needles, pain, pricking, tingling) or negative (numbness). Elementary paraesthesiae are reported to be the most characteristic of seizures arising in the post-central gyrus. ${ }^{56}$ Lewin and Phillips described a patient with the simple partial onset of severe pain arising in the contralateral post-central gyrus. ${ }^{57}$ In pure sensory seizures there is nearly always dysfunction of the part involved, which may be awkwardness, typical sensory ataxia, or paralysis. In the case of the latter, some have referred to these sensory seizures as "inhibitory seizures" - a very controversial phenomenon. ${ }^{58}$ One of the characteristic features of Rolandic seizures is the spread (intracortically) within the Rolandic cortex, e.g., sensory and/or motor, over contiguous parts of the associated homunculus. This, therefore, results in consecutive adjacent parts of the body being involved in seizure activity, which clinically is reflected in a "march" from one place on the body to another. Unlike the tonic activity associated with seizures arising outside of the Rolandic cortex, which often has unreliable localizing and lateralizing value, Rolandic motor activity is clonic and is unambiguously localizing to the contralateral motor cortex in the area of the homunculus from which it arises, and usually is associated with transient post-ictal weakness in the involved part.

\section{Occipital Lobe Seizures}

A visual aura may be positive, consisting of visual phenomena such as flickering lights, spots, lines, images, or negative in which part of the visual field is defective. Epileptic visual hallucinatory auras should be distinguished from migrainous auras, which develop gradually over five minutes and lasts for longer periods of time and with no disruption in the level of consciousness. In this situation, a relatively stereotyped headache usually occurs during or within 60 minutes of the visual aura. Traditionally it has been held that the occipital cortex had the highest threshold with respect to the development of seizures, thus standing in marked contrast to the limbic temporal lobe.$^{59}$ Occipital lobe seizures may be heralded by visual auras, e.g., illusions or hallucinations, but may begin with auras that are more suggestive of nearby neocortex. ${ }^{60}$ When they involve the visual system the involvement will include the contralateral visual (occipital) and/or posterior temporal neocortex. Within this cortex there is a neurophysiological hierarchy, with increasing perceptual sophistication from the cortex of the occipital pole to the posterior temporal cortex. Epileptic discharge in the polar region (Area 17) results in elementary visual features, which lack form, colour, depth, and movement and tend to be fixed in a predictable area of the contralateral visual field. Seizures arising in the more anteriorly situated occipital visual association areas (Areas 18 and 19) exhibit increasing evidence of more elaborate visual hallucinations, with the features of recognizable form, colour, depth, and movement, usually confined to the contralateral half of the visual field. The abnormal epileptic visual abnormalities reach fully developed complex hallucinations from foci in the posterior temporal cortex. These may be illusory, but may represent perfectly normal form with people, environmental structures, landscapes, etc, and involve central vision, occupying the whole of the visual field. Most seizures with these complex visual illusions originate in the non-dominant posterior temporal neocortex. ${ }^{37}$

\section{Caveats}

Seizure semiology has some limitations in lateralizing and localizing the seizure origin. Many semiologic features have high positive predictive values; however, each feature has some potential to falsely localize the seizure onset. ${ }^{3,13}$ False localization should be suspected if the onset of clinical seizures occurs earlier than the onset of ictal EEG discharge. The EEG 
onset should either precede or be simultaneous with the clinical seizure onset. A number of false localizations raise the possibility of multifocal epilepsy. ${ }^{61}$ Several seizures have to be recorded to overcome this possibility. Rathke and colleagues showed that seizure semiology localized seizure onset in only $67 \%$ of patients with multifocal epilepsy. ${ }^{62}$ Another issue that must be remembered is that much of the observational data of seizure semiology has been derived from video-EEG monitored patients with intractable epilepsy. These patients may have semiologic differences when compared to patients with non-intractable epilepsy. As well, some seizures of monitored patients are precipitated by antiepileptic drug withdrawal. ${ }^{63}$ In this situation, the seizure duration and intensity, as well as the likelihood of secondary generalization, are increased. In spite of this, however, available evidence indicates that seizure onset characteristics are not substantially altered and therefore appear to be the same as habitual seizures. ${ }^{64}$ However, rapid generalization can erase the subjective aura from the patient's memory and can give the objective observe increased difficulty in recognizing the individual components of the seizures. Most of the semiologic features that were summarized in Table 4 are useful for hemispheric lateralization, whereas few features are helpful for seizure localization. ${ }^{65,66}$ For example, dystonic limb posturing is more useful for hemispheric lateralization because of its high predictive value; however, it can be observed in seizures arising from either the frontal or temporal lobes. In contrast, bipedal automatisms, such as bicycling movements, are usually observed with frontal lobe seizures, but it does not suggest the side of seizure onset. Therefore, the localizing value of recorded seizures is greater when it is based on concordance of multiple semiologic features than when based on an isolated feature. Lastly it must be noted that most literature descriptions of seizure semiology have been based on adult patients. Temporal lobe epilepsy is more difficult to recognize in children ${ }^{67}$ Childhood TL seizures are less stereotyped and more likely to exhibit prominent tonic posturing or myoclonic jerks. ${ }^{68}$ These motor components become less prominent with increasing age. Likewise, frontal lobe seizures in children appear different from those in adults. ${ }^{69}$ Hyper motor activity, complex motor automatisms, and secondary generalizations are rarely encountered in children. In general, some semiologic features of partial seizures in children increased with age, such as automatisms, unresponsiveness, dystonic posturing, and secondary generalization, while other features decreased with age, such as asymmetric clonic movements and symmetric tonic posturing. ${ }^{70}$

\section{Conclusions}

Seizure history and video recordings should be reviewed carefully to detect as many useful semiologic features as possible. It is essential to record multiple seizures in intractable patients to establish the consistency of the semiologic features, particularly if surgery is considered. A representative seizure should also be shown to the patient's parents or relatives to confirm that habitual seizures were captured. Analysis of the development and sequence of multiple semiologic features can identify the seizure initiation and propagation. This information should be correlated with EEG and MRI findings. Seizure origin is identified more accurately if ictal EEG onset is concordant with seizure semiology. Therefore, the clinical implications of recorded seizures should be assessed in parallel with information from the clinical history, video-EEG, and imaging studies. Clinical semiology is the starting point of understanding a seizure disorder and making the diagnosis of epilepsy. While it may not provide unequivocal evidence of localization of the epileptic focus, nevertheless it usually directs subsequent investigations, whose concordance is necessary for the ultimate localization.

\section{REFERENCES}

1. Jan MM. Clinical review of pediatric epilepsy. Neuroscience. 2005;10:255-64.

2. French JA, Williamson PD, Thadani VM, Darcey TM, Mattson RH, Spencer SS, et al. Characteristics of medial temporal lobe epilepsy. I. Results of history and physical examination. Ann Neurol. 1993;34:774-80.

3. Jan MM. The value of seizure semiology in lateralizing and localizing partially originating seizures. Neurosciences. 2007; 12(3):185-90.

4. Jan MM. The value of postictal electroencephalogram in temporal lobe seizures. Ann Saudi Med. 1999;19:550-3.

5. Jan MM, Sadler M, Rahey SR. Lateralized postictal EEG delta predicts the side of seizure surgery in temporal lobe epilepsy. Epilepsia. 2001;42:402-5.

6. Jan MM, Neville BGR, Cox TC, Scott RC. Convulsive status epilepticus in children with intractable epilepsy is frequently focal in origin. Can J Neurol Sci. 2002;29:65-7.

7. Penry JK, Porter RJ, Dreifuss RE. Simultaneous recording of absence seizures with video tape and electroencephalography: a study of 374 seizures in 48 patients. Brain. 1975;98:427-40.

8. Falconer MA, Taylor DC. Temporal lobe epilepsy: clinical features, pathology, diagnosis, and treatment. In: Price JH, editor. Modern trends in psychological medicine. New York: Appleton-CenturyCrofts; 1970. p. 346-73.

9. Williams D. The border-land of epilepsy revisited. (The Seventh Gowers Memorial Lecture). Brain. 1975;98:1-12.

10. Jan MM. Assessment of the utility of pediatric EEG. Seizure. 2002;11:99-103.

11. Jan MM, Girvin JP. Febrile seizures: update and controversies. Neurosciences. 2004;9:235-42.

12. O'Brien T. Multivariate analysis of historical features and seizure semiology in differentiating frontal lobe from temporal lobeonset epilepsy. Epilepsia. 1998;40:294-8.

13. So EL. Value and limitations of seizure semiology in localizing seizure onset. J Clin Neurophysiol. 2006; 23:353-7.

14. Benbadis S, Kotagal P, Klem G. Unilateral blinking: a lateralizing sign in partial seizures. Epilepsia. 1996;37:45-8.

15. Yen DJ, Su MS, Yiu CH, Kwan SY, Tsai CP, Lin YY. Ictal speech manifestations in temporal lobe epilepsy: a video-EEG study. Epilepsia. 1996;37:45-9.

16. Rego R, Arnold S, Noachtar S. Frontal lobe epilepsy manifesting with seizures consisting of isolated vocalization. Epileptic Disord. 2006;8:274-6.

17. Gabr M, Luders H, Dinner D. Speech manifestations lateralization of temporal lobe seizures. Ann Neurol. 1989;25:82-6.

18. McKeever M, Holmes GL, Russman VS. Speech abnormalities in seizures: a comparison of absence and partial complex seizures. Brain Lang. 1983;19:25-32.

19. Theodore W, Porter R, Penry J. Complex partial seizures: clinical characteristics and differential diagnosis. Neurology. 1983; 33:1115-21.

20. Penfield W, Roberts L. Speech and brain mechanisms. Princeton, NJ: Princeton University Press, 1958.

21. McLachlan, RS. The significance of a history of head and eye turning during seizures. Neurology. 1987;37:1617-9.

22. Fakhoury T, Abou-Khalil B. Association of ipsilateral head turning and dystonia in temporal lobe seizures. Epilepsia. 1995; 36:1065-70. 
23. Kernan JC, Devinsky O, Luciano DJ, Vazquez B, Perrine K. Lateralization significance of head and eye deviation in secondary generalized tonic clonic seizures. Neurology. 1993;43:1308-10.

24. Salanova V, Andermann F, Olivier A, Rasmussen T, Quesney LF. Occipital lobe epilepsy: electroclinical manifestations, electrocorticography, cortical stimulation and outcome in 42 patients treated between 1930 and 1991. Brain. 1992;115: 1655-80.

25. Marks W, Laxer K. Semiology of temporal lobe seizures in lateralizing seizure focus. Epilepsia. 1998;39:721-6.

26. Leutmezer F, Woginger S, Antoni E, Seidl B, Baumgartner C. Asymmetric ending of secondarily generalized seizures. a lateralizing sign in TLE. Neurology. 2002;59:1252-4.

27. Kotagal P, Luders H, Morris HH, Dinner DS, Wyllie E, Godoy J, et al. Dystonic posturing in complex partial seizures of temporal lobe onset. Neurology. 1989;39:196-201.

28. Kotagal P. Lateralizing value of asymmetric tonic limb posturing observed in secondarily generalized tonic-clonic seizures. Epilepsia. 2000:41:457-62.

29. Oestreich LJ, Berg MJ, Bachmann DL, Burchfiel J, Erba G. Ictal contralateral paresis in complex partial seizures. Epilepsia. 1995;36:671-5

30. Kramer RE, Luders H, Goldstick LP, Dinner DS, Morris HH, Lesser RP, et al. Ictus emeticus: an electroclinical analysis. Neurology. 1988;38:1048-52.

31. Baumgartner C, Groppel G, Leutmezer F, Aull-Watschinger S, Pataraia E, Feucht M, et al. Ictal urinary urge indicates seizure onset in the nondominant temporal lobe. Neurology. 2000; 55:432-4

32. Green J. Pilomotor seizures. Neurology. 1984;34:37-9.

33. Jackson JH, Stewart P. Epileptic attacks with a warning of a crude sensation of smell and with the intellectual aura (dreamy state) in a patient who had symptoms pointing to gross organic disease of the right temporo-sphenoidal lobe. Brain. 1899;22:534-49.

34. Penfield W. Temporal lobe epilepsy. Brit J Surg. 1954;41:1-7.

35. Penfield W, Jasper H. Epilepsy and the functional anatomy of the brain. Boston: Little Brown \& Co; 1954. p. 896.

36. Penfield W. The anatomy of temporal lobe seizures. Proc First Int Cong Neurol Sci (Brussels). July 1957. p. 11-12.

37. Mullan S, Penfield W. Illusions of comparative interpretation and emotion. Arch Neurol Psychiat. 1959;81:269-84.

38. Manford M, Fish DR, Shorvon SD. An analysis of clinical seizure patterns and their localizing value in frontal and temporal lobe epilepsies. Brain. 1996;119:17-40.

39. Wada J. Cerebral lateralization and epileptic manifestations. In: Akimoto H, editor. Advances in Epileptology: XIIIth Epilepsy International Symposium. New York: Raven Press; 1982. p. 366-72.

40. Geyer JD, Payne TA, Faught E, Drury I. Postical nose-rubbing in the diagnosis, lateralization, and localization of seizures. Neurology. 1999;52:7443-54.

41. Macrae D. Isolated fear. A temporal lobe aura. Neurology 1954;4: 497-505.

42. Goldberg-Stern H, Gadoth N, Cahill W, Privitera M. Language dysfunction after frontal lobe seizures. Neurology. 2004; 62:1637-8.

43. Ervin FR. Violence and the brain. Trans Coll Physicians Phila. 1972;39:194-203.

44. Walsh GO. Clinical and EEG correlates of an unusually violent psychomotor seizure. Clin Neurophysiol. 1977;42:725.

45. Geschwind N. Interictal behavioral changes in epilepsy. Epilepsia. 1983;24:23-30.

46. Mitchell W, Falconer MA, Hill D. Epilepsy with fetishism relieved by temporal lobectomy. Lancet. 1954;267:626-30.

47. Waxman SG, Geschwind N. Hypergraphia in temporal lobe epilepsy. Neurology. 1974;24:629-36.

48. Florindo I, Bisulli F, Pittau F, Naldi I, Striano P, Striano S, et al. Lateralizing value of the auditory aura in partial seizures. Epilepsia. 2006;47:68-72

49. Geier S, Bancaud J, Talairach J, Bonis A, Szikla G, Enjelvin M. The seizures of frontal lobe epilepsy: a study of clinical manifestations. Neurology. 1977;27:951-8.
50. Geier S, Bancaud J, Talairach J, Bonis A, Enjelvin M, HoosardBouchard H. Automatisms during frontal lobe epileptic seizures. Brain. 1976;99:447-58.

51. Rasmussen T. Characteristics of a pure culture of frontal lobe epilepsy. Epilepsia. 1983;24:482-93.

52. Ludwig B, Ajmone-Marsan C, Van Buren J. Cerebral seizures of probable orbitofrontal origin. Epilepsia. 1975;16:141-58.

53. Waterman K, Purves SJ, Kosaka B, Strauss E, Wada JA. An epileptic syndrome caused by mesial frontal lobe seizure foci. Neurology. 1987;37:577-82.

54. Morris HH 3rd, Dinner DS, Luders H, Wyllie E, Kramer R. Supplementary motor seizures: clinical and electroencephalographic findings. Epilepsia. 1988;29:1075-82.

55. Ajmone-Marsan C, The epileptic seizure: its functional morphology and diagnostic significance: a clinical-electrographic analysis of metrazol-induced attacks. 1957, Springfield, IL: Charles C. Thomas.

56. Mauguiere F, Courjon J. Somatosensory epilepsy: a review of 127 cases. Brain. 1978;101:307-32.

57. Lewin W, Phillips CG. Observations on partial removal of the postcentral gyrus for pain. J Neurol Neurosurg Psychiat. 1952; 15:143-7.

58. Kofman O, Tasker R. Ipsilateral and focal inhibitory seizures. Neurology. 1967;17:1082-6.

59. Gastaut H, Poirier F, Payan H, Salamon G, Toga M, Virouroux M. H.H.E. syndrome. Hemiconvulsions, hemiplegic epilepsy. Epilepsia. 1960; 1:418-77.

60. Boesebeck F, Schulz R, May T, Ebner A. Lateralizing semiology predicts the seizure outcome after epilepsy surgery in the posterior cortex. Brain. 2002;125:2320-31.

61. Krsek P, Tichy M, Hajek M, Dezortova M, Zamecnik J, Zedka M, et al. Successful epilepsy surgery with a resection contralateral to a suspected epileptogenic lesion. Epileptic Disord. 2007; 15:82-9.

62. Rathke KM, Schauble B, Fessler JA, So EL. Reliability of seizure semiology in multifocal epilepsy. Neurology. 2002;58:214.

63. Zhou D, Wang Y, Hopp P, Kerling F, Kirchner A, Pauli E, et al. Influence on ictal seizure semiology of rapid withdrawal of carbamazepine and valproate in monotherapy. Epilepsia. 2002;43:386-93.

64. So EL, Fisch BJ. Drug withdrawal and other activating techniques. In: Engel J, Pedley TA, editors. Epilepsy: a comprehensive textbook. Vol 1. Philadelphia: Lippincott-Raven; 1997. p. 1021-7.

65. Serles W, Caramanos Z, Lindinger G, Pataraia E, Baumgartner C. Combining ictal surface-electroencephalography and seizure semiology improves patient lateralization in temporal lobe epilepsy. Epilepsia. 2000;41:1567-73.

66. Chee MW, Kotagal P, Van Ness PC, Gragg L, Murphy D, Luders HO. Lateralizing signs in intractable partial epilepsy: blinded multiple observer analysis. Neurology. 1993;43:2519-25.

67. Fontana E, Negrini F, Francione S, Mai R, Osanni E, Menna E, et al. Temporal lobe epilepsy in children: electroclinical study of 77 cases. Epilepsia. 2006;47:26-30.

68. Fogarasi A, Jokeit H, Faveret E, Janszky J, Tuxhorn I. The effect of age on seizure semiology in childhood temporal lobe epilepsy. Epilepsia. 2002;43:638-43.

69. Fogarasi A, Janszky J, Faveret E, Pieper T, Tuxhorn I. A detailed analysis of frontal lobe seizure semiology in children younger than 7 years. Epilepsia. 2001;42:80-5.

70. Nordli DR Jr, Kuroda MM, Hirsch LJ. The ontogeny of partial seizures in infants and young children. Epilepsia. 2001;42:986-90. 